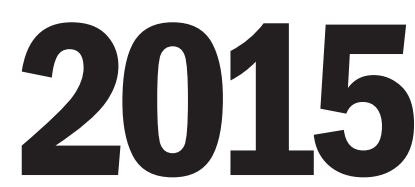

volume 12 | issue 1 an open access journal for architectural research

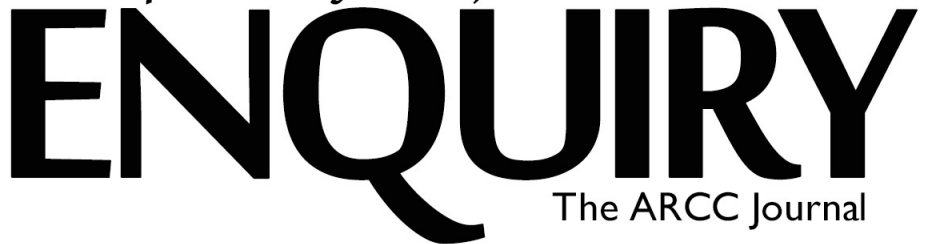

\title{
Daylighting, Space, and Architecture: A Literature Review
}

\author{
Dalia Hafiz
}

\section{ABSTRACT}

Daylighting dynamism and constant change can characterize buildings and spaces with a living quality that cannot be achieved with any other design element. However, daylighting can create unwanted lighting conditions in the visual field causing discomfort and glare. This may affect the performance of building occupants such as workers or students. Consequently, designing for daylighting needs a good understanding of daylighting. Designers can rely on information from simulation software to re-imagine the space, especially to examine possible unexpected visual discomfort conditions.

This paper aims to represent different visual comfort evaluation methods that can help decision-makers make better informed decisions. Different definitions and structures associated with daylight and glare are examined. It also presents a review of the literature of previous research conducted on daylighting, visual comfort analysis and glare studies.

\section{Permissions and copyright}

Authors retain copyright and grant the journal right of first publication with the work simultaneously licensed under a Creative Commons Attribution License that allows others to share the work with an acknowledgement of the work's authorship and initial publication in this journal (Attribution-ShareAlike).

Creative Commons Attribution 3.0 Unported (CC BY 3.0)

You are free to: Share - copy and redistribute the material in any medium or format. Adapt - remix, transform, and build upon the material for any purpose, even commercially. The licensor cannot revoke these freedoms as long as you follow the license terms.

Under the following terms: Attribution - You must give appropriate credit, provide a link to the license and indicate if changes were made. You may do so in any reasonable manner, but not in any way that suggests the licensor endorses you or your use.

No additional restrictions - You may not apply legal terms or technological measures that legally restrict others from doing anything the license permits.

\section{How to cite:}

Hafiz, Dalia. 2015. "Daylighting, Space, And Architecture: A Literature Review." Enquiry 12 (1): 1-8. http://dx.doi.org/10.17831/enq:arcc.v12i1.391

\section{Introduction}

"No space, architecturally, is a space unless it has natural light." Louis Kahn (Loud and Kahn, 1989, P262).

Daylighting is considered one of the main elements of space identification and, consequently is a major component of space quality. It can play a major role in resource conservation, occupants' level of productivity, health and comfort. As suggested by the Heschong Group in their study on student performance in classrooms, views to the outside provided by daylighting have a strong effect on psychological and physical wellbeing (Kleindienst and Andersen, 2009).

Daylighting can create a sense of being in a place; or space phenomenon, which transforms a space into a place where feelings of awareness and dwelling have desirable effects (Haddad, 2010). Norbeg Schulz defines phenomenology as "the exploration and description of phenomena, where phenomena refer to things or experiences as beings experience them" (Parpairi, Baker, Steemers, and Compagnon, 2002). Anything that a person can experience is considered phenomena; an object, event, situation or experience that a person can see, hear, touch, smell, taste, feel, understand, or live through is a phenomenological examination (Parpairi, et al., 2002). Daylighting can participate both positively or negatively in this phenomenological experience.

While daylight is desirable in most living or working spaces it can create uncomfortable situations causing visual discomfort. Several visual discomfort studies were essentially based on light measurements combined with psychophysical procedures; these study methods can be more suitable for researchers and lighting analysts. Other methods depend on space re-imagining and visual representations of glare and visual discomfort conditions, which can be more suitable for designers. The phenomenon of discomfort glare is recognized as one of the most common visual problem that has not been fully quantified and understood. This paper aimed at presenting necessary definitions and summarizing the literature and previous research findings on daylighting, glare and visual comfort. To achieve the intended goal different classifications of visual comfort related applications were explored. In addition a comparison of these methods and limitations was presented. 


\section{Daylighting Phenomena}

The phenomenology of human existence, joy and sense of dwelling inside the place are enhanced by the powerful connection with the outside environment; this may be realized when natural light is present and evokes feelings of comfort and satisfaction with the visual environment. Consequently daylighting as a science should not become more important than the architectural quality resulting from the visually inspiring daylighting design (Steemers, 1994). Since vision is the most developed of our senses, it is important to ensure visual comfort by controlling glare and ensuring appropriate patterns of contrast (Yin, 2011).

\section{Visual Comfort}

Visual comfort is defined as the state of mind that expresses satisfaction with the visual environment. It is a human need that can affect task performance, health, safety, mood and atmosphere (Park, Augenbroe, and Messadi, 2003). Visual comfort problems are often experienced in our lives every day, in offices, movie theaters, libraries, leaving and arriving from and to a metro stations or when entering and exiting a building. Visual comfort has two dimensions:

1. The quantitative (measurable): where enough light can provide the required visibility. If we clearly and correctly see the visual environment we may be satisfied with it.

2. The qualitative (immeasurable): which is the elimination of disturbing effects related to the lighting: a visually comfortable space has minimal disturbing effects (Werner Osterhaus, 2009).

Studies have been conducted to evaluate visual comfort. As an example, visual comfort in offices was investigated by Osterhaus (2009) using a case study approach. This research concluded that no efficient integrated systems that combine daylighting and electric lighting were provided. The research findings suggested ways to better integrate computer work stations in day lit offices. Many studies focused on the required conditions for visual comfort in educational buildings. The results of these studies showed a positive relationship between increased daylighting and improved test scores and better student performance. Interior space quality and users' perception was investigated in another study by $\mathrm{Xu}$ (1984). It concluded that future investigations using different prediction techniques were needed to improve the predictive control algorithm.

Furthermore, a visual comfort simulation tool for artificially lit buildings was presented in the research entitled "A Hypertextual Tool for Comfort". It was found that this tool could assist users to validate the electrical lighting condition of their existing design measurements and calculations, even designs with irregular shapes. It could also help predict comfort by either inputting values into the tool, or through simulation of the features of the building and its external climatic conditions (Filippi, Astolfi, and Piccablotto, 2000). A study conducted by Reinhart and Wienold (2010) investigated daylighting analysis based on climatic metrics, glare analysis and occupant comfort. This research explored computer-based daylighting analysis capabilities to predict daylight availability, occupant comfort, occupant behavior and energy use. In addition, this research explored obstacles such as multiple simulation software operation and long simulation time. Identifying suitable daylighting performance metrics targets was an unsolved issue in this research. (Newsham and Veitch, 2001) explored occupants preferred illuminances in office spaces by giving them control over a dimmable lighting system. Finally a study entitled "Animated Building Performance Simulation" investigated possible ways to link 3D modeling tools with advanced daylighting simulation tools. This tool represented a significant step towards integration of a parametric design process with performance analysis (Pointer, 1986).

\subsection{Visual Comfort Evaluation Methods}

There are key factors that need to be considered when applying a daylighting and visual comfort study including: building orientation, sky condition, climate characteristics (weather data). Based on these factors there are eight calculation methods used to evaluate lighting conditions and visual comfort examined in the literature. The eight methods are: 1) The Illuminating Engineering Society of North America (Linstone and Turoff, 1975)(VCP) method, 2) Glare Index, 3) Brightness Ratio, 4) Unified Glare Rating, 5) Radiance method or Glare perception, 6) Daylight Glare Probability (DGP), 7) Daylight autonomy, and 8) Useful Daylight Illuminance, as will be explained in the following subsections:

\subsubsection{The IESNA method (Visual Comfort Probability)}

For a given lighting scheme, the Visual Comfort Probability (VCP) is a metric used to rate lighting scenes. It is defined as the percentage of people that will find a certain scene (viewpoint and direction) comfortable with regards to visual glare (Jakubiec and Reinhart, 2011). The IESNA handbook stated that discomfort glare is not a problem in lighting conditions when the following conditions are satisfied: the visual comfort probability (VCP) is $70 \%$ or more at the given view angles: varying from 60 to -60 degrees, with 0 representing the center of the field of view. In addition, the ratio of the maximum luminance to the average luminaire luminance should not exceed $5: 1$ at $45^{\circ}, 55^{\circ}$, $65^{\circ}, 75^{\circ}$, and $85^{\circ}$ from the lowest point for crosswise and lengthwise viewing (Miller, Boyce, and Ngai, 2001). The IES advised that direct solar exposure illuminance that exceeds 1000 lux will cause discomfort (Linstone and Turoff, 2011).

The limitations of the IESNA method (the visual comfort probability method) are summarized in Figure 1:

- A fixed initial illuminance of $1000 \mathrm{~lx}(100 \mathrm{fc})$ is used.

- Predetermined room surface reflectance is used.

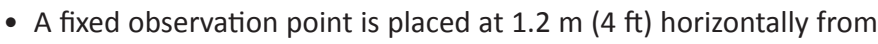

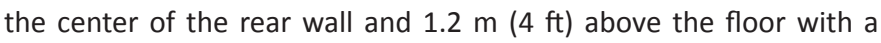
horizontal line of sight looking directly forward.

- A limited field of view angle $\left(53^{\circ}\right.$ from the line of sight of the observer) is defined.

\subsubsection{The Glare Index}

Glare is defined as the difficulty seeing in the presence of bright light resulting from a direct or reflected light source in the visual field. It is typically expressed as the ratio of the size, location and luminance of glare sources in a field of view when compared to the average luminance 


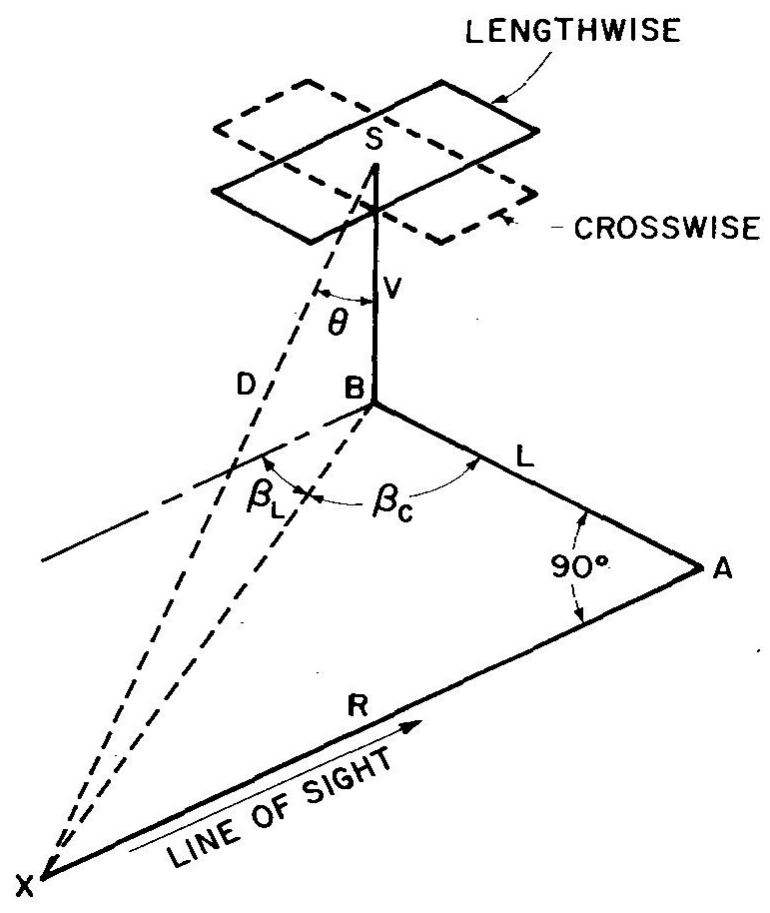

Figure 1: $(\mathrm{S})$ position of the luminaire, $(\mathrm{X})$ observation point

not inclusive of the glare source (Berkeley, 2012; Chauvel, Collins, Dogniaux, and Longmore, 1982; CIE., 1983).

In general, there are two types of glare:

- Disability glare: Glare that can result in a significant decrease in visual performance and visibility, accompanied by discomfort glare.

- Discomfort glare: Glare causing discomfort, not necessarily obstructing visual performance or visibility.

Some previous studies were based on the Glare Index (GI) method. The GI predicts the presence of discomfort glare due to daylighting. Factors affecting the glare index include the size and relative position of the openings, sky and interior luminance. The Glare Index is a unit-less index of visual comfort. It can be calculated via computer software such as RADIANCE and DAYSIM using the IESNA handbook equations (Araji, Boubekri, and Chalfoum, 2007).

The Daylight Glare Index is a derivative method, but for daylighting.

$$
D G I=10 \log _{10} 0.48 \sum_{i=1}^{n} \frac{L_{s}^{1.6} \cdot \Omega_{s}^{0.8}}{L_{b}+0.07 \omega_{s}^{0.5} L_{s}}
$$

(Equation 1)

Where,

If DGI > 31 Intolerable, < 18 Barely Perceptible
Although the DGI is one of the main indexes for the daylight glare evaluation, especially for sources with non-uniform luminance, some previous research opposed using DGI as a reliable glare index for the following reasons:

- Instrumental limits: including difficulties calculating luminance values and solid angles. In addition the geometrical parameters $\omega$ and $\Omega$ are evaluated using diagrams which are only valid when the line of sight is perpendicular to the window and passing through one of the lower corners, which does not apply to all cases.

- Interpretative limits: the simplification of the window plane uniformity zoning (sky, obstructions and ground) could lead to conflicting or simplified results.

- Conceptual limits: the background is not properly considered in the DGI formula. The solid angle of the background is not considered, apart from its luminance level.

- Evaluation limits: Some researchers showed that DGI sometimes overestimated glare when compared to other metrics especially under clear sky conditions (Institution, 2015).

\subsubsection{Brightness Ratio method}

This method compares the measured brightness "luminance" of points in the visual field. According to ISO standards contrast ratios above three are necessary to preserve readability. More contrast is suggested for low luminance values "below $10 \mathrm{~cd} / \mathrm{m} 2$ " (Cooper, Gallegos, and Granof, 1995).

In research conducted by Araji and Bobekry (2007), based on Lambert's law (a surface obeying the law has the same luminance in every direction) illuminance ratio was used instead of luminance ratio to evaluate visual comfort. Illuminance is defined as the total density of the luminous flux incident on a surface, per unit area. It gives the information on how much the incident light illuminates the surface. It can be measured in footcandle or Lux, 1 Lux= (1Lumen/m2) (Guha, Shim, and Woo, 2004; Linstone and Turoff, 1975; REA, 2010). On the other hand, luminance is defined as the amount of light passing through a particular area and falling within a given solid angle. Luminance is measured in Candella/ meter2 or (nits) (Cottam, Roe, and Challacombe, 2004; REA, 2010). Physical illuminance values were measured from a scale model with readings taken using light sensors. These sensors were placed on fixed stationary points situated along a path in the study space. The points were placed $2.4 \mathrm{~m}$ apart (based on the average pedestrian speed, 20 seconds is the total time needed to cross this transitional space. However, the most common luminance ratio thresholds are shown in Table 1.

W Osterhaus (2002) identified three visual field zones (the central zone, where the visual task takes place; the adjacent zone delimited by a cone of 60 degrees; and the non-adjacent zone, delimited by a wider cone of 120 degrees) characterized by luminance ratios of $1: 3: 10$. This ratio is based on the idea that the luminance in the visual field of someone who is doing a static task must remain within reasonable ratios in order to prevent glare, which could cause visual discomfort. Other tasks required different ratios; for example: 


\begin{tabular}{|l|l|}
\hline Display Effect & Subjective apparent brightness ratio \\
\hline Subtle & $2.5: 1$ \\
\hline Moderate & $5: 1$ \\
\hline Strong & $7: 1$ \\
\hline Dramatic & $10: 1$ \\
\hline
\end{tabular}

Table 1: Brightness Ratio threshold and display effect (Araji, et al., 2007, Rowe andWright, 1999)

\section{- 3:1 or 1:3 between paper and VDU screen,}

- $3: 1$ or 1:3 between the visual task (paper or screen) and the adjacent surfaces,

- $10: 1$ or $1: 10$ between the visual task and the non-adjacent surfaces (Newsham and Veitch, 2001). The adjacent and non-adjacent surfaces are represented by two cones of 60 and 120 degrees, as shown in 2:

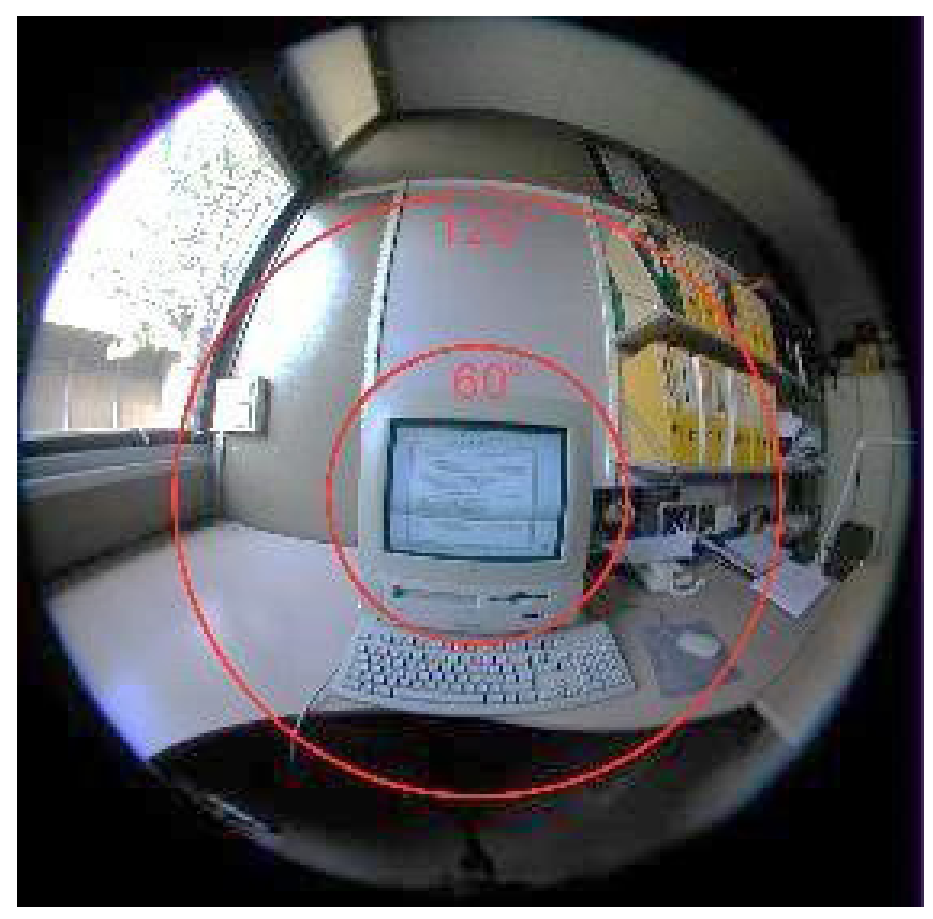

Figure 2: Field of view (Newsham and Veitch, 2001)

The occupants' preferred maximum to minimum luminance ratio in the field of view was investigated in many studies, ratios of 1:5, 1:10 and 1:20 were previously declared. A digital video photometer was used in a previous research to look at a grid of squares of approximately $1^{\circ}(15 \times 15$ pixels $)$ in size. The mean luminance of each square in the field of view was measured, the maximum square to the minimum square were compared. This method will clearly yield a much greater range of luminance values and luminance ratios. From their results, (Loe, Mansfield, and Rowlands, 1994) suggested that the maximum-tominimum luminance ratio in the field of view be between 10 and 50 .
The brightness ratio method proposed some assumptions which produced limitations to the applied experience:

- In some research using this method, to obtain numerical values, illuminance was used instead of luminance based on Lambert's law.

- A linear relationship was assumed between horizontal diffused illuminance and adaptation luminance.

- Artificial sky was used, which means only overcast sky conditions were considered.

\subsubsection{Unified Glare Rating (UGR)}

UGR is defined as the log of the glare from the lamps in the visual field divided by the background visible light from the room.

$$
\mathrm{UGR}=8 \log \left[\frac{0.25}{\mathrm{~L}_{\mathrm{b}}} \sum\left(\frac{\mathrm{L}^{2} \omega}{\mathrm{p}^{2}}\right)\right]
$$

(Equation 2)

Where $L$ is the luminance, is the solid angle between viewer's eye and the luminaire, $p$ is the Guth index and is the background luminance. Glare increases with brighter lamps and lower background lighting and conversely decreases with dimmer lamps and more background luminance (Park, Augenbroe, and Messadi, 2003).

If $U G R<10$ : Glare is insignificant and can be ignored.

If UGR > 31: Glare is intolerable (Rea, 2000). A detailed glare threshold and criterion is shown in Table 2

\begin{tabular}{|l|l|}
\hline Glare criterion & UGI \\
\hline Just imperceptible & 10 \\
\hline Perceptible & 16 \\
\hline Just acceptable & 19 \\
\hline Unacceptable & 22 \\
\hline Just Uncomfortable & 25 \\
\hline Uncomfortable & 28 \\
\hline Just Intolerable & 31 \\
\hline
\end{tabular}

Table 2: UGR threshold and criterion (Rea, 2000)

\section{Method limitation:}

- Glare calculation is based on artificial lighting from ceiling fixtures only as shown in Figure 3

\subsubsection{The Daylight Factor}

A daylight factor is the ratio of the internal light level to the external light level and can be expressed as follows:

$$
\mathrm{DF}=(\mathrm{Ei} / \mathrm{Eo}) \times 100 \%
$$

(Equation 3) 

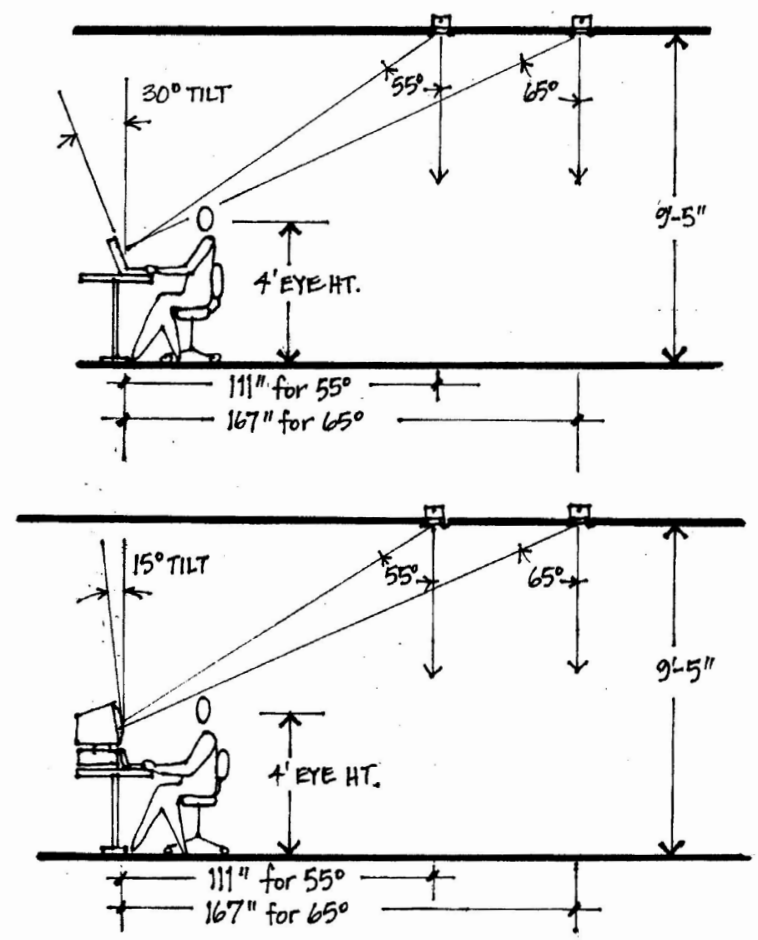

Figure 3: Horizontal illuminance glare on tabletop near keyboard

Where, $\mathrm{Ei}=$ illuminance due to daylight at a point on the indoor working plane and Eo $=$ outdoor illuminance on a horizontal plane from the clear hemisphere of an overcast sky. DF thresholds depend on the building function; they can generally be expressed as follows:

- $\quad$ Under 2: Not adequately lit - artificial lighting will be required.

- $\quad$ Between 2 and 6: sufficiently day lit.

- $\quad$ Over 5: Well lit-artificial lighting generally not required except at dawn and dusk - but glare and solar gain may cause problems.

The daylight factor was originally developed to examine overcast conditions, which is considered a limitation when examining clear sky and direct sun conditions (Weinold and Christoffersen, 2005).

\subsubsection{The Daylight Glare Probability (DGP)}

This method is a relatively new approach for glare prediction. It is an empirical approach based on the vertical eye illuminance as well as the glare source luminance, its solid angle and its position index (Harvard, 2006). DGP calculation considers the overall brightness of the view, position of glare sources and visual contrast. This method provides a strong connection to the user response concerning glare sensitivity when compared to other existing glare models.

While Ev= Vertical illuminance at eye level (Lux), Ls is the luminance of the source $(\mathrm{cd} / \mathrm{m} 2), \omega$ is the solid angle of the source $(\mathrm{sr})$ and $P$ is the Guth position index.

$$
\mathrm{DGP}=5.87 \times 10^{-2} E_{v}+\frac{9.18 \times 10^{-2} \cdot \log \left(1+\sum L_{s i}^{2} \cdot \omega_{s i}\right)}{\left[\left(E_{v}^{c 4} \cdot P_{v i}^{2}\right)+0.16\right]}
$$

Term 1

Term 2

(Equation 4)

For Term 1: the measurable visual comfort aspects depend on the vertical eye illuminance (which may be calculated using DAYSIM software) and Term 2 includes visual comfort aspects that depend on the detected glare sources: solid angle and position index, size, and luminance can only be calculated from an image rendering.

A simplified method to calculate the DGP was presented by Wienold (2009). This method shows a reasonable glare perception judgment when considering only vertical space illuminance at eye level and neglecting other illuminance directions. Therefore, a simplified DPG (DGPs) was found (Weinold and Christoffersen, 2005).

$$
\mathrm{DGPs}=6.22 \times 10^{-5} E_{v}+0.184
$$

(Equation 5)

Analysis of the DGPs-values and the glare rating categories of the user glare discomfort assessments are presented in Table 3

\begin{tabular}{|l|l|l|l|}
\hline & & & $95 \%$ confidence interval \\
\hline Upper limit & Lower limit & Avg & Glare rating \\
\hline 0.352 & 0.314 & 0.33 & Imperceptible \\
\hline 0.398 & 0.356 & 0.38 & Perceptible \\
\hline 0.448 & 0.39 & 0.42 & Disturbing \\
\hline 0.59 & 0.464 & 0.53 & Intolerable \\
\hline 0.352 & 0.314 & 0.39 & Avg \\
\hline
\end{tabular}

Table 3: Analysis of the DGPs-values and the glare rating categories of the user assessments (Kensek and Suk, 2011a)

DGP is not defined for values smaller than 0.2 or if the vertical illuminance is below 320 Lux. Based on the user's assessment a correction factor was applied to the existing DGP equation to extend the usability range were the illuminance curve is between 0 and 300 Lux- Equation 6 and Figure 4 .

\subsubsection{Daylight Autonomy (DA)}

Daylight autonomy (DA) predicts the percentage of daylight hours where the illuminance meets or exceeds the desired task illuminance level. Continuous daylight autonomy ( $\mathrm{CDA}$ ) is similar to $\mathrm{DA}$; the only difference is that CDA considers partial credit for daylight levels below a user-defined threshold in a linear fashion (Chatzikonstantinou, 2015).

Method limitations: DA is considered only as a quantitative measure. DA does not give partial credit for daylight levels below the user-defined lux threshold which may cause an overestimation of electric lighting energy use (Chatzikonstantinou, 2015). 


$$
D G P \_ \text {lowlight }=D G P \frac{e^{0.024^{*} E_{V}-4}}{1+e^{0.024^{*} E_{V}-4}}
$$

(Equation 6)

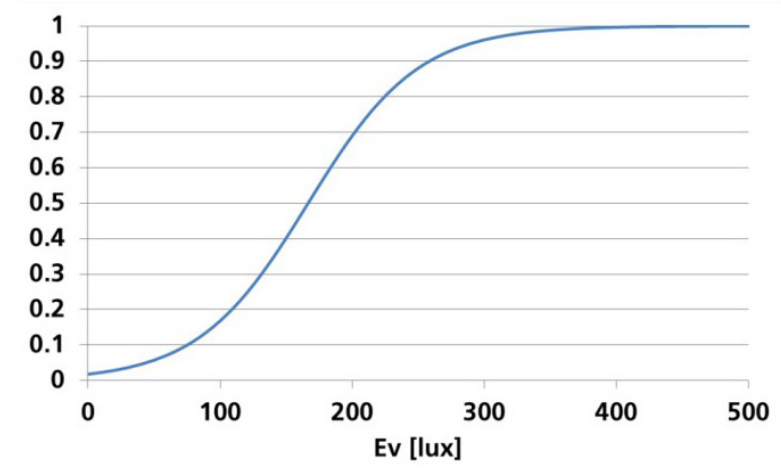

Figure 4: Low light correction (Grynberg, 1989)

\subsubsection{Useful Daylight Illuminance (UDI)}

Useful daylight illuminances are defined as the illuminances that fall within the range 100-2000Lx Figure 5

This range is based on data from comprehensive field studies of occupant behavior under day lit conditions. It can be explained as follows:

1. Useful illuminance range (100-2000 Ix);

2. Insufficient illuminance (less than $100 \mathrm{~lx}$ );

3. Extreme illuminance (greater than $2000 \mathrm{~lx}$ )

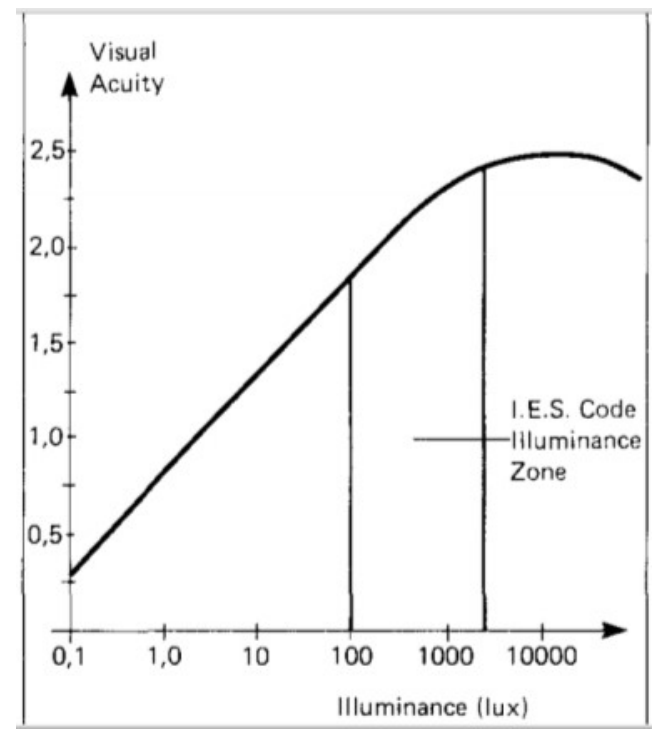

Figure 5: Visual acuity as a function of illuminance (Bruel and kjaer, 1982)
The UDI helps to communicate the significant characteristics of climatebased analyses gained from daylight autonomy in addition to considering daylighting dynamism and human factors. The UDI approach provides a simple, yet meaningful assessment of daylight and solar penetration together using realistic, climate-based conditions (Pesudovs, Patel, Bradbury, and Elliott, 2002).

\subsection{Visual Comfort Evaluation Methods Comparisons}

Research by Heschong et al. (1999) discussed the variety of users needs that can help them select the best daylighting performance metrics. It presented a Daylighting Analysis Framework that included all the inputs and outputs of a simulation tool.

In the research by Nazzal, 2005 Index values were related for (CGI, DGI and UGR) to discomfort probability (for DGP) and comfort probability (for VCP) to Hopkinson's 1950 categorical rating scheme for discomfort glare as shown in Table 5:

\begin{tabular}{llllll}
\hline & DGP & DGI & UGR & VCP & CGI \\
\hline Imperceptible & $<0.35$ & $<18$ & $<13$ & $80-100$ & $<13$ \\
Perceptible & $0.35-0.40$ & $18-24$ & $13-22$ & $60-80$ & $13-22$ \\
Disturbing & $0.40-0.45$ & $24-31$ & $22-28$ & $40-60$ & $22-28$ \\
Intolerable & $>0.45$ & $>31$ & $>28$ & $<40$ & $>28$ \\
\hline
\end{tabular}

Table 5: Glare index values relation

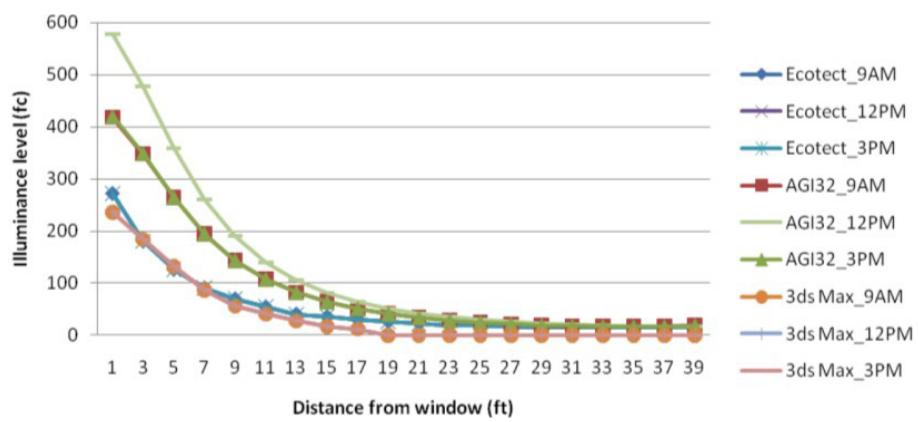

Figure 6: Illuminance output using different software (Kensek and Suk, 2011b)

\subsubsection{Visual comfort methods limitations and assumptions} Although daylighting analysis data can come from computer simulations, physical models, high-dynamic range imagery (HDR) generated from a computer simulation or a camera, or field measurements it is important to understand each method limitations as shown in the following subsections:

\section{Physical modeling-based tools Limitations}

1. Due to proximity both simple and complex artificial skies have geometric modeling errors that require some calculation error analysis to overcome some of their limitations (Creswell, 1999). 
2. Due to the finite dimensions, horizon errors may occur because of the ratio between the model size and the dome size, adjustment factors are needed to overcome this error.

3. The artificial light used in the procedures change its outputs with temperature and age, dirt accumulation and applied voltage which may affect the illuminance outputs (Mitroff and Turoff, 2002).

\section{Computer-based based tools limitations}

1. One major limitation of the daylighting computer simulations is in creating geometry modeling and materials (ex: windows have to be modeled as surfaces with zero thickness) which may generate complexity in the model and may require more time and effort.

2. Model complexity generated by the modeling detailing may produce larger files and need better computing capabilities consequently simple models are needed.

3. Some 3D modeling software need translation or sub components which require many steps to be transferred to an input file for a daylighting simulation tools.

4. Some daylighting tools can work with one 3D modeling software and not the others (Kota, Haberl, Clayton, and Yan, 2014).

5. Some simulations tools provide illuminance from one direction only (ex: vertical illuminance) and not full range of illuminance directions which can affect the outcomes accuracy.

6. Several tools do not take into account internal obstructions (furnishing, occupants, etc.), and bidirectional transmissions. Therefore, simulation results will be confronted to reference test cases (Hasson, Keeney, and McKenna, 2000).

\section{Field measurements limitations}

1. The measurement devices; Luxmeter or Luminance meter readings errors,

2. The human factor errors in using the instrument while taking readings,

3. Variable weather conditions; variable sky conditions may occur in short times which is likely to affect the measurements,

4. Camera lens characteristics and lighting exposures variation which is likely to affect the collected images.

\section{Previous Research Gaps}

The literature addressed the impact of visual comfort on the quality of the place and on the occupants. Few studies however focused on visual comfort under daylighting conditions and fewer still considered the design process and how design decisions are made relative to visual comfort. Previous research gaps were also found to be visual comfort in the early stages of design. Furthermore, the spatial and time dynamism of daylighting are important factors when designing for daylighting, they are not typically considered in the early stages of design. The study of daylighting is moving from a static captured scene to an annual quantitative analysis, while the qualitative visual aspects are sometimes not fully addressed. In addition, visual adaptation process and eye direction needed to be examined when trying to avoid visual discomfort especially in day lit spaces.

\section{Conclusion and future work}

The main goal of this paper was to provide guidance to the designers to make better design decisions through the understanding of visual comfort evaluation methods. From the examination of the different daylighting and glare evaluation metrics it was concluded that there are no special metrics for visual comfort evaluation. The metrics used are initially for glare analysis; some of them were previously used for visual comfort analysis. Although research on daylighting metrics developments suggested that luminance based lighting controls have the potential to provide occupant satisfaction over traditional illuminance based lighting controls, there is no full agreement on illuminance limit values (Yin, 2011). Hence it is suggested in this research that multiple metrics are used in the analysis of visual comfort in day lit spaces. It is also proposed that both luminance and illuminance-based metrics with associated thresholds are used in the daylighting evaluation process.

It is recommended that future applications would review a series of papers that compare two or three evaluation techniques in depth to provide an approach for visual comfort evaluation. It is important to mention that different building functions require different thresholds; more application on suitable visual comfort metrics and thresholds for elderly and visually impaired is important. Finally, extended research on the comfort phenomenon is needed to examine different aspects influencing occupants comfort including thermal condition, acoustics, and mood.

\section{References}

Cottam, H., Roe, M., and Challacombe, J. (2004). Outsourcing of trucking activities by relief organisations. Journal of Humanitarian Assistance, $1(1)$.

Creswell, J. W. (1999). Mixed-method research: Introduction and application. Handbook of educational policy, 455-472. http://dx.doi. org/10.1016/B978-012174698-8/50045-X

Guha, S., Shim, K., and Woo, J. (2004). REHIST: Relative error histogram construction algorithms. Paper presented at the Proceedings of the Thirtieth international conference on Very large data bases-Volume 30. http://dx.doi.org/10.1016/b978-012088469-8.50029-2

Haddad, E. (2010). Christian Norberg-Schulz's Phenomenological Project In Architecture. Architectural Theory Review. http://dx.doi. org/10.1080/13264821003629279

Hasson, F., Keeney, S., and McKenna, H. (2000). Research guidelines for the Delphi survey technique. Journal of advanced nursing, 32(4), 10081015.

Heschong, L., Mahone, D., Kuttaiah, K., Stone, N., Chappell, C., and McHugh, J. (1999). Daylighting in schools: An investigation into the relationship between daylighting and human performance. Summary for the Pacific Gas and Electric Company on behalf of the California Board for Energy Efficiency Third Party Program. 
Institution, S. (2015). Smithsonian Institution. from www.si.edu

Kensek, K., and Suk, J. Y. (2011). Daylight Factor (overcast sky) versus Daylight Availability (clear sky) in Computer-based Daylighting Simulations. Journal of Creative Sustainable Architecture \& Built Environment, CSABE, 1.

Kleindienst, S., and Andersen, M. (2009). The adaptation of daylight glare probability to dynamic metrics in a computational setting. Paper presented at the Proceedings of the Lux Europa 2009 Conference. Lausanne, September 9e11.

Kota, S., Haberl, J. S., Clayton, M. J., and Yan, W. (2014). Building Information Modeling (BIM)-based daylighting simulation and analysis. Energy and Buildings, 81(0), 391-403. http://dx.doi.org/10.1016/j. enbuild.2014.06.043

Linstone, H. A., and Turoff, M. (1975). The Delphi method: Techniques and applications (Vol. 29): Addison-Wesley Reading, MA.

Loe, L., Mansfield, K., and Rowlands, E. (1994). Appearance of lit environment and its relevance in lighting design: experimental study. Lighting Research and Technology, 26(3), 119-133. http://dx.doi. org/10.1177/096032719402600301

Miller, N. J., Boyce, P. R., and Ngai, P. Y. (2001). A metric for judging acceptability of direct luminaires in computer offices. Journal of the Illuminating Engineering Society, 30(2), 12-29. http://dx.doi.org/10.10 80/00994480.2001.10748350

Mitroff, I., and Turoff, M. (2002). 11. B. Philosophical and methodological foundations of Delphi.

Newsham, G. R., andVeitch, J. A. (2001). Lighting quality recommendations for VDT offices: a new method of derivation. Lighting Research and Technology, 33(2), 97-113. http://dx.doi. org/10.1177/136578280103300205

Osterhaus, W. (2009). Design Guidelines for Glare-free Daylit Work Environments.

Park, C.-S., Augenbroe, G., and Messadi, T. (2003). Daylighting optimization in smart facade systems. Paper presented at the Proceedings of the Eighth International IBPSA Conference.

Parpairi, K., Baker, N., Steemers, K., and Compagnon, R. (2002). The Luminance Differences index: a new indicator of user preferences in daylit spaces. Lighting Research and Technology, 34(1), 53-66. http:// dx.doi.org/10.1191/1365782802li030oa

REA, M. S. (2010). IESNA Lighting Handbook Reference and Application.

Reinhart, C. F., and Wienold, J. (2010). The Daylighting Dashboard A Simulation-Based Design Analysis for Daylit Spaces. Building and Environment (August 2010).

Yin, H. (2011). Glare studies: Comparison of three glare indices, HDR imaging and measured values: University of Southern California.

Bowles, T. A. (2007, October). Grounded Theory. Introduction to Qualitative Research in Adult \& Higher Education. Lecture given at North Carolina State University, Raleigh, N.C.

Chaffee, John. Thinking Critically. Boston, Mass.: Houghton Mifflin Co, 1988. Print.
Charmaz, Kathy. Constructing Grounded Theory: A Practical Guide Through Qualitative Analysis. London: Sage Publications, 2006. Print.

Creswell, John W. Qualitative Inquiry and Research Design: Choosing Among Five Approaches. Thousand Oaks, Calif.: Sage Publications, 2007. Print.

Dryzek, John S. The Politics of the Earth: Environmental Discourses. Oxford, England: Oxford University Press, 1997. Print.Guy, Simon, and Steven Moore. "Sustainable Architecture and the Pluralist Imagination." Journal of Architectural Education (2007): 15-23. Print.

Lemke, J. L. Talking Science: Language, Learning, and Values. Norwood, N.J.: Ablex Publishing Corporation, 1990. Print.

Mark, Laura. "Five Views on Sustainability in Architectural Education." The Architects' Journal (2013). ProQuest. Web. November 17, 2014.

Patton, Michael Quinn. Qualitative Research and Evaluation Methods. Thousand Oaks, Calif.: Sage Publications, 2002. Print.

Rawes, Peg. Relational Architectural Ecologies: Architecture, Nature and Subjectivity. New York: Routledge, 2013. Digital.

Schwandt, Thomas A. The SAGE Dictionary of Qualitative Inquiry. Los Angeles, Calif: SAGE, 2007. Print.

Strauss, Anselm L., and Juliet M. Corbin. Basics of Qualitative Research: Techniques and Procedures for Developing Grounded Theory. Thousand Oaks, Calif.: Sage Publications, 1998. Print.

Teymur, Necdet. Environmental Discourse: A Critical Analysis of Environmentalism in Architecture, Planning, Design, Ecology, Social Sciences and the Media. London, England: Question Press, 1982. Print. 